06

\title{
Исследование зеренной структуры мишеней SmS, полученных при различных условиях
}

\author{
(C) И.С. Волчков, Е.Б. Баскаков, В.И. Стрелов, В.М. Каневский \\ ФНИЦ „Кристаллография и фротоника“ РАН, \\ Москва, Россия \\ E-mail: Volch2862@gmail.com
}

Поступило в Редакцию 29 апреля 2019г.

В окончательной редакции 29 апреля 2019 г.

Принято к публикации 23 июля 2019г.

Исследована зеренная структура образцов мишеней $\mathrm{SmS}$, полученных методами прессования без использования и с использованием последующей высокотемпературной обработки токами высокой частоты (ТВЧ) под различным давлением. Определена плотность образцов, созданных при разных условиях. Найдены оптимальные технологические условия получения качественных мишеней моносульфида самария: ТВЧ-отжиг с прессованием под давлением в $5 \mathrm{t} / \mathrm{cm}^{2}$ более эффективен, чем ТВЧ-отжиг с прессованием под давлением в $4 \mathrm{t} / \mathrm{cm}^{2}$. Установлено значительное содержание несвязанного металлического самария в образцах, полученных прессованием под давлением в $5 \mathrm{t} / \mathrm{cm}^{2}$, но не прошедших высокотемпературный ТВЧ-отжиг.

Ключевые слова: сульфид самария, зеренная структура, растровая электронная микроскопия.

DOI: 10.21883/PJTF.2019.22.48641.17859

Полупроводниковые материалы на основе моносульфида самария $(\mathrm{SmS})$ являются перспективными для создания $n$-типа термоэлектрогенераторов (ТЭГ). Они обладают высокой термической стабильностью, значительной термоэлектродвижущей силой $(\sim 30 \mathrm{mV}$ при $513 \mathrm{~K})$ [1] и электропроводностью $\left(\sim 550 \Omega^{-1} \cdot \mathrm{cm}^{-1}\right)[2]$. $\mathrm{SmS}$ также обладает аномальным эффектом [3] - генерацией электродвижущей силы при нагреве, происходящей в отсутствие градиента температуры [4-6]. Этот эффект назван термовольтаическим эффектом. Перечисленные свойства моносульфида самария обусловливают перспективность его использования в качестве основы для ТЭГ. При этом следует отметить, что термовольтаический эффект был обнаружен и на других полупроводниках $[7,8]$, однако на данный момент использование $\mathrm{SmS}$ является более предпочтительным ввиду высокого КПД возможных ТЭГ, созданных на его основе [9]. Кроме того, интерес к термовольтаическому эффекту обусловлен тем, что на его основе возможно создание и других электронных устройств $[3,10]$, в частности газовых сенсоров [10].

Термовольтаический эффект в $\mathrm{SmS}$ принято связывать с наличием в моносульфиде самария дефектных ионов $\mathrm{Sm}^{2+}$ [11]. Место расположения дефектных ионов в кристаллической решетке $\mathrm{SmS}$ предположительно соответствует вакансиям подрешетки $\mathrm{S}$, при этом часть вакансий остается незаполненной [6]. Вместе с тем дефектные ионы распределяются в $\mathrm{SmS}$ неравномерно по всему образцу, что и приводит к генерации электродвижущей силы при нагреве. Данное объяснение механизма генерации электродвижущей силы справедливо только для $\mathrm{SmS}$, имеющего состав, близкий к стехиометрическому. В этом случае наблюдается диссоциация $\mathrm{SmS}$ на $\mathrm{Sm}$ и $\mathrm{Sm}_{3} \mathrm{~S}_{4}$, происходящая в процессе температурной обработки образцов $\mathrm{SmS}$ при $1800 \mathrm{~K}$ [12].

Использование $\mathrm{SmS}$ в качестве основы для ТЭГ, используемых в микроэлектронике, подразумевает создание качественной тонкой пленки моносульфида самария. Данные тонкие пленки получаются методами ионного, лазерного, взрывного и магнетронного распыления [1316]. На качество пленок влияют не только условия получения, но и структура и состав мишени $\mathrm{SmS}$, используемой в качестве источника напыления $[13,15,16]$, что объясняет повышенные требования к качеству и составу мишеней $\mathrm{SmS}$.

Перспективность использования $\mathrm{SmS}$ в качестве основы для ТЭГ определяет необходимость дальнейших работ по его исследованию, в том числе изучение образцов мишеней моносульфида самария, полученных в различных условиях. Данные исследования позволят отработать методику получения качественных мишеней $\mathrm{SmS}$, необходимых для получения тонких пленок моносульфида самария, пригодных для создания ТЭГ.

В качестве объектов исследования использовались серии образцов мишеней моносульфида самария, полученные методами прессования без использования и с использованием последующей высокотемпературной обработки токами высокой частоты (ТВЧ). Каждая серия состояла из трех образцов, имеющих идентичные геометрические размеры и плотность. Элементный анализ образцов мишеней $\mathrm{SmS}$ и оценка зернистости материала проводились методом растровой электронной микроскопии (РЭМ) с использованием РЭМ Jeol JCM-6000 PLUS в режиме вторичных электронов $(10 \mathrm{kV})$, укомплектованного рентгеновским энергодисперсионным спектрометром. Определение элементного 

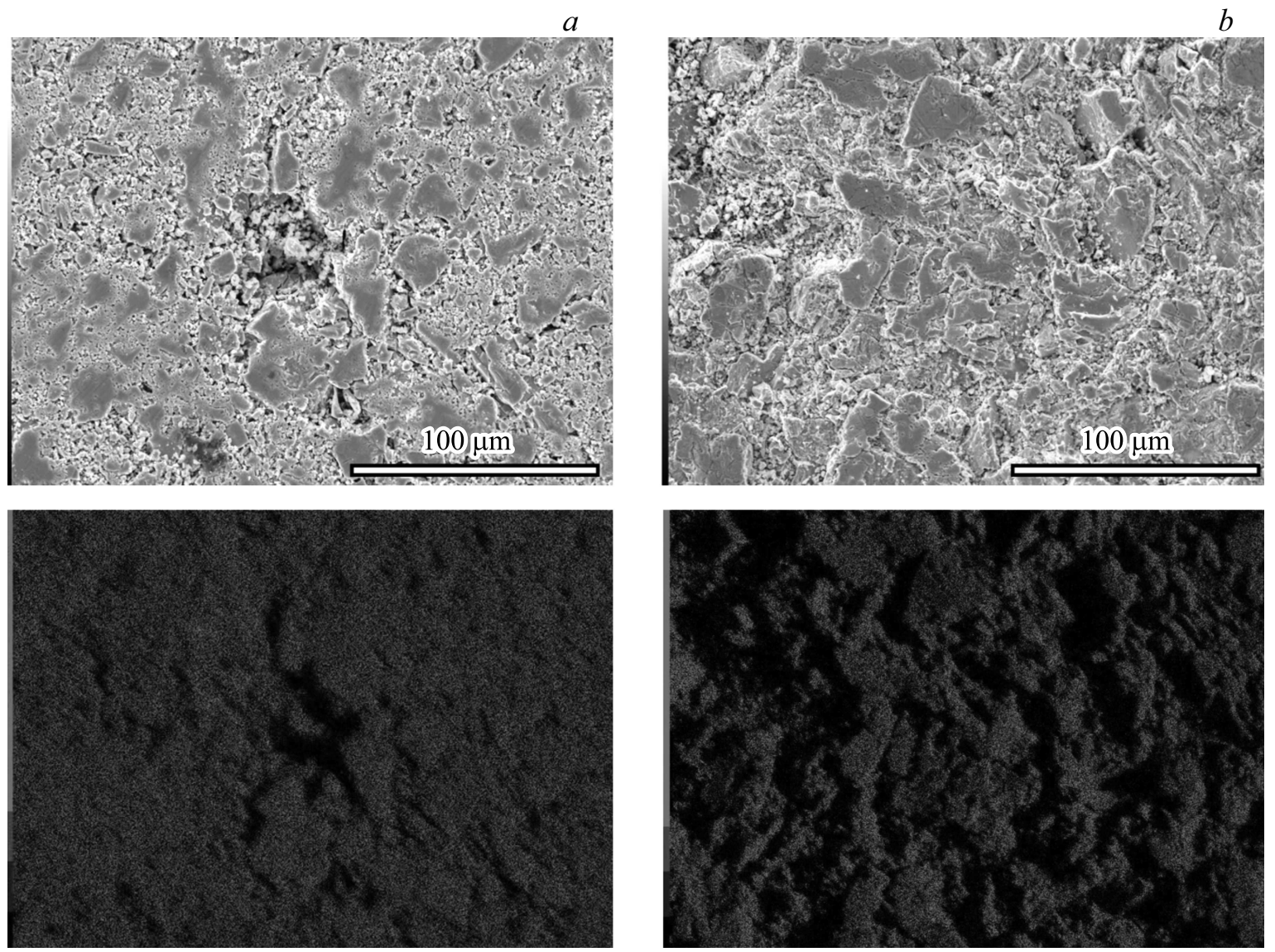

Рис. 1. РЭМ-изображения поверхности образцов $\mathrm{SmS}$ и карты распределения элементов по $\mathrm{Sm}$ и $\mathrm{S}$ (черные точки - несвязанный $\mathrm{Sm}$, серые точки - области, содержащие $\mathrm{Sm}$ и S). $a$ - образец № $1, b$ - образец № 2.
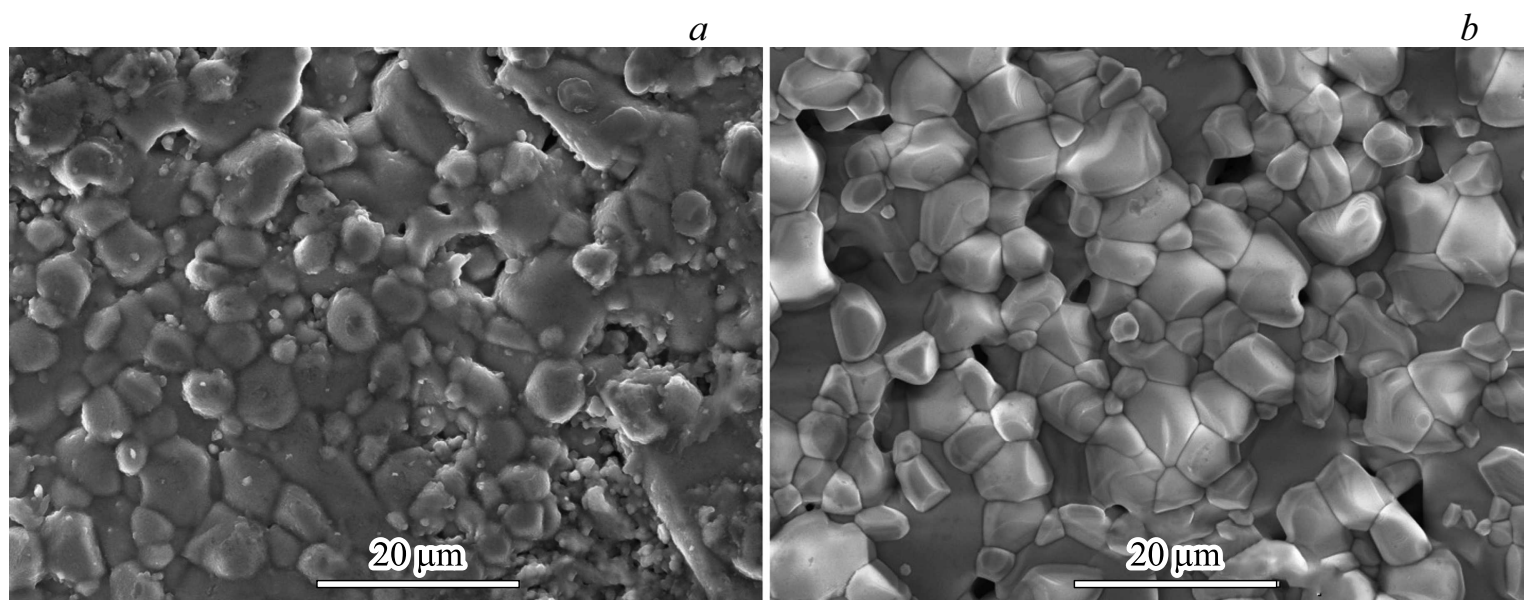

Рис. 2. РЭМ-изображения поверхности образцов $\mathrm{SmS}$, прошедших ТВЧ-отжиг. $a$ - образец № 3 , $b$ - образец № 4 .

состава и построение карт распределения элементов в образце осуществлялись с помощью РЭМ Jeol JCM-6000 PLUS. Для получения точной статистики проводилась серия снимков-анализов на исследуемой области. Все образцы мишеней моносульфида самария были изготовлены в виде спрессованных цилиндров, имеющих высоту $2.5 \mathrm{~mm}$ и радиус $10 \mathrm{~mm}$. Оценка плотности образцов выполнялась с помощью стандартного метода расчета плотности через определение массы и объема образцов $\mathrm{SmS}$. Масса образцов измерялась с помощью аналитических весов AND GH-252, имеющих показатель дискретности 0.01/0.1 mg. Измерение 
Результаты оценки размеров зерен и плотности исследуемых образцов $\mathrm{SmS}$

\begin{tabular}{c|c|c|c|c}
\hline Образец SmS & $\begin{array}{c}\text { Режим прессования: } \\
P, \mathrm{t} / \mathrm{cm}^{2}\end{array}$ & $\begin{array}{c}\text { Высокотемпературный } \\
\text { ТВЧ-отжиг при } 1900 \mathrm{~K}\end{array}$ & $\begin{array}{c}\text { Средний размер } \\
\text { зерна, } \mu \mathrm{m}\end{array}$ & $\begin{array}{c}\text { Плотность } \\
\text { образцов, } \mathrm{g} / \mathrm{cm}^{3}\end{array}$ \\
\hline № 1 & 4 & Не проводился & - & 4.98 \\
№ 2 & 5 & “ & - & 5.01 \\
№ 3 & 4 & Проводился & $\sim 5$ & 5.38 \\
№ 4 & 5 & “ & Агломераты $\sim 15-25[13]$ & 5.53 \\
SmS & - & - & $<60[17]$ & $5.64[18]$ \\
(лит. данные) & & & &
\end{tabular}

объема проводилось с помощью электронного штангенциркуля Vernier с реальной погрешностью измерения $0.05 \mathrm{~mm}$.

Исходный порошок моносульфида самария для всех исследуемых образцов был получен путем стандартного ампульного синтеза. Для образцов № 1,3 и № 2,4 порошок прессовался в цилиндрическую форму под давлением 4 и $5 \mathrm{t} / \mathrm{cm}^{2}$ соответственно. Образцы № 3 и 4 подвергались высокотемпературному ТВЧ-отжигу при температуре 1900 К. Необходимость исследований методами РЭМ обусловлена тем, что образцы мишеней $\mathrm{SmS}$, полученные в различных условиях, имеют разную зеренную микроструктуру [15]. Как видно из таблицы, образцы № 3 и 4 обладают более высокой плотностью, чем образцы № 1 и 2, что указывает на усадку объема, происходящую в процессе высокотемпературного отжига, что соответствует данным, представленным в работе [15].

Как показали исследования, микроструктура образцов мишеней, полученных при разных давлениях, существенно различается. На рис. 1 показана микроструктура образцов № 1 и 2. Образец № 2 обладает более плотной микроструктурой, чем образец № 1, что происходит из-за более высокого давления, прикладываемого к образцу в процессе прессования. При этом карты распределения по $\mathrm{Sm}$ и $\mathrm{S}$ показывают, что образец № 2 имеет значительные области несвязанного самария, в то время как в образце № 1 области несвязанного самария минимальны.

Образцы № 3 и 4 имеют ярко выраженную зеренную микроструктуру (рис. 2). При этом образец № 3 имеет меньшие по размеру зерна со слабовыраженными гранями по сравнению с образцом № 4. Распределение $\mathrm{Sm}$ и S в приповерхностных слоях образцов идентично. Образец № 4 обладает плотностью, близкой к литературным данным для моносульфида самария (см. таблицу). Исходя из условий получения образцов мишеней № 3 и 4, а также из результатов анализа зеренной микроструктуры можно говорить о наличии в этих образцах избыточных ионов $\mathrm{Sm}$, так как известные данные соответствуют представленным в работе [15].

При напылении тонких пленок методом магнетронного напыления важным фактором качества получаемых пленок является скорость перехода материала мишени в газовую фазу, а также постоянство данной скорости в течение всего процесса. Для достижения стабильной скорости роста используемая мишень должна обладать плотностью, близкой к плотности стехиометрического соединения, во избежание паразитного газообразования в процессе распыления материала мишени. При этом зернистость мишени также должна быть как можно более равномерной для исключения неконтролируемого изменения скорости распыления материала.

Результаты исследований образцов мишеней № 1 и 2, полученных стандартным ампульным синтезом и прессованием, свидетельствуют о неоднородности микроструктуры. Кроме того, данные образцы имеют малую плотность по сравнению с эталонной плотностью $\mathrm{SmS}$. Наличие несвязанного самария в структуре образцов № 1 и 2 позволяет говорить о некотором разнообразии фаз, что согласуется с результатами работы [15], в которой сообщается о значительном разнообразии фаз $(\mathrm{SmS}$, $\left.\mathrm{Sm}_{3} \mathrm{~S}_{4}, \mathrm{Sm}_{2} \mathrm{~S}_{3}\right)$ в образцах, полученных в схожих условиях. Таким образом, данные образцы не удовлетворяют описанным выше требованиям, предъявляемым к мишеням, используемым для магнетронного распыления.

Образцы мишеней № 3 и 4 обладают плотностью более близкой к приведенным в литературе значениям для моносульфида самария, чем используемые на данный момент мишени при магнетронном напылении тонких пленок $\mathrm{SmS}$ [13]. Кроме того, в работе [13] зерна $\mathrm{SmS}$ преимушественно состоят из агломератов фракции $15-25 \mu \mathrm{m}$ и более мелких частиц размером 2-6 $\mu \mathrm{m}$ против зерен размером 5-10 $\mu$ д для образцов № 4. В результате более близкая к эталонной плотности $\mathrm{SmS}$ плотность мишеней № 4, меньший разброс размеров зерен, а также соответствие температурных условий получения, необходимых для образования избыточных ионов $\mathrm{Sm}$ [12], позволяют предположить, что мишени, созданные в данных условиях, являются оптимальными для получения качественных тонких пленок $\mathrm{SmS}$ методом магнетронного распыления. Образцы № 3 являются менее удовлетворительными из-за большей пористости, слабо сформированной зеренной структуры по сравнению с образцом № 4, что негативно влияет на процесс магнетронного напыления и, как следствие, на качество пленок [16].

\section{Финансирование работы}

Работа выполнена с использованием оборудования ЦКП ФНИЦ „Кристаллография и фотоника“ РАН при 
поддержке Министерства науки и высшего образования РФ в рамках работ по государственному заданию ФНИЦ „Кристаллография и фотоника“ РАН.

\section{Конфликт интересов}

Авторы заявляют, что у них нет конфликта интересов.

\section{Список литературы}

[1] Каминский В.В., Гревцев М.А., Казанин М.М., Шаренкова Н.В. // Письма в ЖТФ. 2017. Т. 43. В. 23. С. 62-68.

[2] Miodushevsky P.V. // 2001 ICEP Proc. Tokyo, Japan, 2001. P. 336-339.

[3] Грошев И., Полухин И. // Компоненты и технологии. 2014. № 8. С. $150-157$.

[4] Казанин М.М., Каминский В.В., Соловьев С.М. // ЖТФ. 2000. T. 70. В. 5. C. $136-138$.

[5] Васильев Л.Н., Каминский В.В. // ФТТ. 1994. Т. 36. В. 4. C. $1172-1175$.

[6] Каминский В.В., Голубков А.В., Васильев Л.Н. // ФТТ. 2002. T. 44. В. 8. С. $1501-1505$.

[7] Пронин И.А., Аверин И.А., Божсинова А.С., Георгиева А.Ц., Димитров Д.Ц., Карманов А.А., Мошников В.А., Папазова К.И., Теруков Е.И., Якушова Н.Д. // Письма в ЖТФ. 2015. Т. 41. В. 19. С. 23-29.

[8] Саидов А.С., Лейдерман А.Ю., Каршиев А.Б. // Письма в ЖТФ. 2016. Т. 42. В. 14. С. 21-27.

[9] Егоров В.М., Каминский В.В., Казанин М.М., Соловьев С.М., Голубков А.В. // Письма в ЖТФ. 2015. Т. 41. B. 8. C. $50-54$.

[10] Пронин И.А., Якушова Н.Д., Димитров Д.Ц., Крастева Л.К., Папазова К.И., Карманов А.А., Авери И.А., Георгиева А.Ц., Мошников В.А., Теруков Е.И. // Письма в ЖТФ. 2017. Т. 43. В. 18. С. 11-16.

[11] Голубков А.В., Гончарова Е.В., Капустин В.А., Романова М.В., Смирнов И.А. // ФТТ. 1980. Т. 22. В. 12. C. $3561-3567$.

[12] Голубков А.В., Сергеева В.М. // ЖВХО. 1981. Т. 26. В. 6. C. $645-653$.

[13] Бамбуров В.Г., Андреев О.В., Иванов В.В., Воропай А.Н., Горшков А.В., Полковников А.А., Бобылев А.Н. // ДАН. 2017. T. 473. № 6. C. 676-680.

[14] Andreev O.V., Ivanov V.V., Gorshkov A.V., Miodushevskiy P.V., Andreev P.O. // Eurasian Chem.-Technol. J. 2016. V. 18. N 1. P. 55-65.

[15] Высоких А.С., Миодушевский П.В., Андреев П.О. // Вестн. ТюмГУ. 2011. № 5. С. 179-185.

[16] Стрелов В.И., Баскаков Е.Б., Бендрышев Ю.Н., Каневский В.М. // Кристаллография. 2019. Т. 64. № 2. C. $281-284$.

[17] Каминский В.В., Васильев Л.Н., Романова М.В., Соловьев С.М. // ФТТ. 2001. Т. 43. В. 6. С. 997-999.

[18] Самсонов Г.В., Дроздова С.В. Сульфиды. М.: Металлургия, 1972. С. 86. 